\title{
On-the-Job Specific Training and Efficient Screening
}

\author{
Mehmet Bac, Bilkent University, Turkey
}

Employment relationships are governed by short-term incomplete contracts and typically involve on-the-job screening and firm-specific training. This article studies a dynamic employment relationship with these features and identifies a potential conflict between the employer's twin objectives to screen and train the worker: when the training technology is quite productive, the employer may have to sacrifice from worker performance during the screening process. The article thus offers an explanation for why firms may invest suboptimally on training, which complements the standard "inappropriable rents" explanation based on ex post mobility of young employees.

\section{Introduction}

Employment relationships have three important aspects. First, they are typically governed by short-term incomplete contracts due to prohibitive costs of defining and verifying "worker performance." Second, there is asymmetric information regarding the matching outcome, or potential workers' innate abilities to supply (noncontractible) "performance." This information problem can be alleviated by a screening process. ${ }^{1}$ Third, workers' productivity may improve over time through specific bilateral learning and human capital investments that, often, are also noncontractible. An example in which such investments are observed is academics, where some departments allocate research funds to assistant professors on

${ }^{1}$ See Waldman (1984), Greenwald (1986), and Abe (1994) for the adverse selection phenomenon is labor markets. The personnel data studied by Baker, Gibbs, and Holmstrom (1994) indicate that employers learn about their workers' unobservable characteristics during the relationship and that this learning affects workers' wage profiles.

[Journal of Labor Economics, 2000, vol. 18, no. 4]

(C) 2000 by The University of Chicago. All rights reserved.

0734-306X/2000/1804-0004\$02.50 
a nonexclusive basis, which the assistant professor complements with his or her own effort and investment to improve research, administrative, and teaching abilities. These investments are in part relationship specific: the department's investment on the assistant professor is sunk, while the assistant professor's effort, perhaps with the exception of the publication record, is not entirely observable to outsiders.

This article studies a dynamic employment relationship with the three main features mentioned above. When worker performance is not contractible and potential workers retain private information about their matching parameters, a major concern of the employer is to screen out workers with "bad" matching parameters as early as possible, then build up a relationship with a good match and jointly invest to develop specific human capital. The purpose of the present article is to highlight a tradeoff that the employer may face in pursuing these objectives; screening efficiency may have to be sacrificed given the employer's postcontract incentives to invest in the worker's specific human capital, or, alternatively, the productivity of the investment technology may have to be reduced in order to induce an efficient screening process. Moreover, when this trade-off is effective, it is likely to influence the worker's career wage profile.

I present a 2-period employer-worker game that starts with the employer's contract (wage) offer to a pool of observationally identical workers. The selected worker then chooses (i) an effort that determines his actual performance and (ii) an investment on his employer-specific human capital simultaneously with the training expenditures of the employer. The employer makes a continuation decision at the end of the first period if the contract is a short-term probationary contract. If she opts for continuation with the incumbent worker, the parties negotiate the terms of the second contract.

All equilibria of this game display an increasing pattern of wages due to the combined impact of matching considerations, information revelation, and the incumbent worker's improved specific human capital, which affects his bargaining power in negotiating future wages. The efficient screening arrangement that attracts only "good" worker types stipulates a relatively high first-contract wage. This relatively high wage could induce a temporary but efficient effort during the probationary contract. However, given also the employer's investment incentives, a "bad" worker type who foresees the equilibrium path may accept the contract, penetrate into the relationship, supplement the employer's investment with his own best reply, generate a sufficient improvement in his specific human capital, and lock the employer in for the second contract. This possibility upsets the screening process. The employer should then either induce a nonscreening equilibrium (offer a contract accepted by all 
worker types) or an inefficient screening equilibrium, given the investment technology in place.

This article highlights a new source of inefficiency in investment on employer-specific human capital. In labor relationships governed by incomplete contracts, there is a potential conflict between the employer's objectives to perform efficient on-the-job screening and train the specific skills of the workers. This conflict may lead the employer to induce an equilibrium with inefficient level of specific investment. ${ }^{2}$ The model also provides insights about the determinants of wage profiles within firms. Comparing the screening and nonscreening equilibria produces a standard prediction of on-the-job training models (see Demougin and Siow [1994, 1996] and Malcomson [1997] for references): wage profiles are steeper for workers who get, and invest more on, training. It also produces a prediction of sorting models based on private information of the workers (see Weiss [1995] for an assessment): wage profiles are steeper for workers who go through probationary contracts than those who do not. I show that the joint presence of screening considerations and specific human capital accumulation may produce a steeper wage profile than predicted by models based on one of these two features and, thus, that the potential conflict between specific training investments and efficient screening can further contribute to the "slope" of the wage profile. This conclusion is more likely to hold if the investment technology is highly productive.

At a more general level, this article is related to an extensive literature on dynamic contractual relationships. The problem of designing an incomplete contracting procedure that provides protection against opportunism under asymmetric information has been studied by Farrell and

\footnotetext{
${ }^{2}$ One reason why the employer-specific investment level may be suboptimal is complementarity between general and employer-specific abilities. Alternatively, it may be impossible to decompose human capital investments into their general and specific components. In the case of bilateral human capital investments, an additional source of inefficiency arises due to strategic considerations, as one party would optimally reduce his investment level if the other party invests more. As Acemoglu and Pischke (1998a) show, labor market imperfections such as turnover costs and ex post monopsony power can provide employers with some incentives to invest on workers' general skills. The impact of labor market imperfections is to transform technologically general skills into specific skills. Acemoglu and Pischke (1998b) study a two-period model based on the firms' ex post monopsony power to explain their expenditures on general training. My focus in this article is employer-specific investments. Abe (1994) and Prendergast (1992) provide adverse selection models with investments in specific skills and study equilibrium labor turnover. Bac and Saglam (1999) study the interplay of unobservable, specific human-capital accumulation, promotion criteria, and managerial defections. These papers do not consider on-the-job screening in the presence of bilateral specific investments.
} 
Shapiro (1989) and Bac $(1993,1997) .{ }^{3}$ The message of these papers is that using a short-term contracting procedure with potential negotiation for continuation terms is a better protection against opportunistic behavior. Under an incomplete long-term contract that specifies future terms of exchange (wages), one of the parties (the worker) can manipulate noncontractible aspects of exchange (withhold performance) to the expense of the other party (the employer). In such environments, short-term probationary contracts can perform screening and potentially improve performance by implicitly linking performance to continuation. The new aspect considered in this article is the inclusion of bilateral investments that provide direct benefits to one of the parties (the employer) and indirect benefits to the other (the worker, through improved bargaining power to negotiate better continuation terms).

The article is organized as follows. Section II develops a dynamic game-theoretic model of the employer-worker relationship. The game is analyzed in Section III. Section IV concludes and discusses empirical ramifications of the results. The proofs are gathered in the appendix.

\section{Model}

An employer demands one unit of labor per period. She faces a pool of potential workers with a reservation wage of $w_{R}>0$. Worker performance, denoted $P$, is not contractible. ${ }^{4}$ A performance-relevant matching parameter, $\theta$, is privately known by the workers. I assume two possible realizations of $\theta, \theta_{H}$ and $\theta_{L}$, with $\theta_{H}>\theta_{L}$. Let $\pi$ denote the probability that a worker is of type $\theta_{H}$.

There are 2 periods, and no discounting is assumed for simplicity. In each period, worker performance depends on two variables: effort $e_{t}$ and

${ }^{3}$ That menus of contracts can induce self-selection and, hence, mitigate asymmetric information and screening problems is well known. A class of dynamic models (see Laffont and Tirole 1988) where output or performance is contractible and information is asymmetric generate the result known as the ratchet effect: potential continuation has a negative effect on present effort incentives. Holmstrom (1982) shows that career concerns can reverse the ratchet effect. In Bac (1993, 1997), potential continuation of the relationship enhances present effort incentives by providing a motive of signaling a good match parameter. The mechanism that generates effort despite contract incompleteness in these models is the agent's expectation of capturing a sufficient continuation surplus; the same mechanism can also produce successful signaling/screening early in the relationship. These effects will be operating in the present model as well.

${ }^{4}$ A possible interpretation is that the employer's job offer has idiosyncratic attributes, so that she has to develop a bilateral relationship with a worker to get improved performance in the future. The job can be thought of as a "nonport" job (Doeringer and Piore 1971), partly protected from outside market forces. For simplicity, I assume that the reservation wage $w_{R}$ does not depend on the privately known matching parameter of the workers. 
employer-specific human capital that supplements the matching parameter $\theta$. Given the incumbent worker's type $\theta$, the effort $e_{t}$ exerted in period $t$ generates performance according to the simple technology $P(\theta$, $\left.F, e_{t}\right)=(\theta+F)+e_{t}$, where $F$ is the worker's accumulated specific human capital, initially normalized to be zero. The employer observes $P$ and $F$, but not $e_{t}$.

The incumbent worker's specific human capital $F$ can grow through bilateral, noncontractible investments. The worker's and the employer's investments $y_{W}$ and $y_{E}$ will generate an improvement in the worker's performance by $F\left(y_{W}, y_{E}\right)$ in the next period. I assume that the function $F\left(y_{W}, y_{E}\right)$ is increasing and strictly concave. Investment decisions are made in period one, simultaneously (hence under imperfect information), and observed at the end of period one. The matching parameter $\theta$ and specific human capital $F$ are thus substitutes in this model; this specification simplifies the exposition without qualitatively affecting the results. ${ }^{5}$

The parties' objective functions are specified as follows. The employer's per-period utility $u_{E}=P-w-y_{E}$ depends directly on the performance of the worker, the wage, and her investment decision. Denoting effort disutility by $d(e)$, the corresponding expression for the incumbent worker is $u_{W}=w-d(e)-y_{W}$.

In the last period, noncontractibility of performance blocks the employer's way in providing effort incentives, hence the worker will withhold effort and offer the performance $\theta+F\left(y_{W}, y_{E}\right)$. However, firstperiod effort that temporarily improves performance may be positive, as I show, thanks solely to the incumbent worker's incentive to signal his type.

The contractible variables in this model are the wage $w$ and the duration of contracts. Thus, the relationship will be governed either by a "long-term" contract $\left\{w_{1}, w_{2}\right\}$ where the wages for the 2 periods are specified (possibly including a high breach penalty to ensure that the parties do not renege on its terms) or a "short-term" contract $\left\{w_{1}\right\}$ that includes no commitments for continuation. Here, commitment for continuation to period two is a dominated option for the employer, and accordingly, I focus on short-term contractual arrangements. As the analysis in Section III will make clear, the only reason why the incumbent worker accepts the short-term contract offer and invests on specific human capital despite the hazard of termination is the anticipated link to his second-period wage: the worker's performance and investment $y_{W}$

${ }^{5}$ The potential conflict between the screening and investment motives of the employer exists under complementarity as well, but the analysis of this case is slightly more complex. 
signal information and increase his value for the employer, thus also his bargaining power at the contract-renewal stage. A long-term contract that guarantees continuation at the prespecified wage $w_{2}$ eliminates this link and, thereby, the incumbent worker's incentive to invest on employerspecific skills. ${ }^{6}$

Thus, the sequence of events under short-term contracting is as follows. The employer makes the initial offer, workers make acceptance decisions, and the employer picks one among those who accept. During the first period, the worker chooses $\left(e_{1}, y_{W}\right)$, and the employer chooses $y_{E}$, paying the wage $w_{1}$. The employer observes performance and investments as the first period expires and updates her beliefs about the incumbent worker's type. The revised probability that she faces a $\theta_{H}$-worker given $P_{1}$ and $y_{W}$ is denoted $\mu\left(\theta_{H} \mid P_{1}, y_{W}\right)$. At this stage, the employer either keeps the incumbent worker $(b=1)$ or terminates and switches to another worker $(b=0)$. If the employer picks the first option, the parties proceed to the negotiation stage where their relative bargaining power determines the wage for the second contract. ${ }^{7}$ The bargaining power may be split between the incumbent worker and the employer at the interimcontract renewal stage because parity between the incumbent worker and outsiders may not obtain due to transmission of matching information and accumulation of specific human capital. The model thus captures a salient feature of real-life employment relationships: their transformation into a bilateral monopoly.

Below I postulate a solution to the interim negotiation problem and

${ }^{6}$ The observation that long-term contracts are (weakly) dominated does not depend on the presence of an investment technology. Long-term contracts provide protection against opportunism when there is external uncertainty and all trade-relevant variables are contractible or there are contractible sufficient statistics for the relevant variables. If, as in the present model, certain key aspects of trade are not contractible, the employer can only be worse off by committing herself to continuation and paying prespecified wages because the worker can manipulate noncontractible performance. See Bac $(1993,1997)$ for a discussion of this phenomenon and Bac (1998) for an application to a buyer-seller context.

7 The evolution of the parties' relative bargaining power is thus an important component of the analysis. I do not assume that the employer retains all the bargaining power in all circumstances. To be precise, the employer has all the bargaining power whenever there is at least one other worker available who is observationally identical to the incumbent worker. The employer can induce Bertrand-type competition among the seemingly identical workers and capture the surplus. If the employer cannot induce such competition, the employer and the incumbent worker will each have some bargaining power. In this setting, no individual worker ever has all the bargaining power with respect to the employer, for the employer is unique and trade with her promises a net nonnegative surplus. The employer has all the bargaining power at the initial stage because she faces a pool of seemingly identical workers. 
later incorporate this solution into the definition of the equilibrium of the extensive-form game. Suppose that the employer terminates her relationship and hires another worker. Since performance is not contractible and there is 1 period to go, the employer will not be able to screen out workers with bad matching parameters. Accordingly, the employer's optimal wage offer leaves all worker types indifferent, that is, $w_{2}=w_{R}$. This yields $U_{E}^{X}=\pi \theta_{H}+(1-\pi) \theta_{L}-w_{R}$ as the expected value of the employer's outside option. Given investments $y_{W}, y_{E}$ and the employer's beliefs $\mu$, any wage $w_{2}$ that yields more than $U_{E}^{X}$ would make a positive continuation surplus for the employer. On the other hand, since the incumbent worker's disagreement utility is the reservation wage $w_{R}$, he will obtain a positive surplus from any wage above $w_{R}$. Therefore any negotiated second-period wage $w_{2}\left(\mu, y_{W}, y_{E}\right)$ from the interval $\left[w_{R}, w_{R}\right.$ $\left.+\left(\theta_{H}-\theta_{L}\right)(\mu-\pi)+F\left(y_{W}, y_{E}\right)\right]$ is mutually beneficial. Note that if the incumbent worker has signaled no type information nor accumulated any specific human capital, $\mu=\pi, F=0$, and the employer is indifferent between continuation and termination, which implies that the only possible second period wage is $w_{2}=w_{R}$. The employer will terminate the relationship if $F=0$ and $\mu=0$ (the worker reveals a bad match and no investment is made).

The wage $w_{2}\left(\mu, y_{W}, y_{E}\right)$ represents the anticipated outcome of bargaining. In internal labor markets, it may be determined by administrative rules and custom that govern the pricing of labor. When continuation is mutually beneficial, thus, chosen by the employer, I assume that the negotiated wage $w_{2}\left(\mu, y_{W}, y_{E}\right)$ splits the total expected surplus $\left(\theta_{H}\right.$ $\left.-\theta_{L}\right)(\mu-\pi)+F\left(y_{W}, y_{E}\right)$ proportionately. The share $\beta$ goes to the incumbent worker, and the share $1-\beta$ goes to the employer. Note that the case $\beta=0.5$ corresponds to the Nash bargaining solution when $\mu=0$ or $\mu=1$.

The expected utilities of the incumbent worker and the employer can respectively be written as follows:

$$
\begin{aligned}
& U_{W}=w_{1}-d\left(e_{1}\right)-y_{W}+b w_{2}\left(\mu, y_{W}, y_{E}\right)+(1-b) w_{R}, \\
& U_{E}=P_{1}-w_{1}-y_{E}+b V+(1-b)\left[\pi \theta_{H}(1-\pi) \theta_{L}-w_{R}\right] .
\end{aligned}
$$

In (2), $V=\mu \theta_{H}+(1-\mu) \theta_{L}+E\left\{F\left(y_{W}, y_{E}\right)-w_{2}\left(\mu, y_{W}, y_{E}\right)\right\}$ is the employer's second period expected utility. Expected first-period performance is $P_{1}=\pi \theta_{H}+(1-\pi) \theta_{L}+e_{1}^{*}$ if $\left\{w_{1}\right\}$ is a nonscreening contract and $P_{1}=\theta_{H}+\hat{e}_{1}$ if it is a screening contract that attracts only $\theta_{H^{-}}$-workers.

The solution concept for this game is Perfect Bayesian Equilibrium (PBE). Given her updated beliefs, the employer's continuation decision 
must be optimal; investment decisions during the first period must be best replies to each other, and the worker's acceptance and effort choices (contingent on being selected) must be optimal. The employer's initial choice of contractual arrangement must also be optimal, given the induced continuation equilibrium. The employer's belief system is an important component of equilibrium construction, postulated here as $\mu\left(\theta_{H} \mid P_{1}, y_{W}\right)=1$ if both $P_{1} \geq \bar{P}$ and $y_{W} \geq \bar{y}$, and $\mu\left(\theta_{H} \mid P_{1}, y_{W}\right)=0$ otherwise. I impose the Intuitive Criterion on beliefs off the equilibrium path, which also serves to determine $\bar{P}$ and $\bar{y}$ endogenously. According to these beliefs, on observing a performance or investment that falls short of the threshold $\bar{P}$ or $\bar{y}$, the employer believes that she faces a $\theta_{L}$-worker. ${ }^{8}$ A standard tie-breaking assumption will ensure that a $\theta_{L}$-worker rejects a contract proposal if he is indifferent between accepting and rejecting.

Since the two worker types are initially observationally identical and have the same reservation wage, any contract $\left\{w_{1}\right\}$ that is accepted by a $\theta_{L}$-worker will also be accepted by a $\theta_{H}$-worker. The latter has a matching advantage in any continuation equilibrium. Thus, potential types of equilibria include those in which $\theta_{L}$-workers are screened out and those in which both types of workers accept the initial contract to work for at least one period. The latter type of (nonscreening) equilibria can further be classified according to whether the worker types "separate" or "pool together" at the end of the first contract (whether $\mu \in\{0,1\}$ or $\mu=\pi$ ). Since a screening PBE cannot be of the pooling type, the game has three potential types of PBE: screening-separating, nonscreening-separating, and nonscreening-pooling. The last of these three, as I show below, cannot arise under the Intuitive Criterion given the matching advantage of the $\theta_{H^{-}}$worker.

\section{Analysis}

Consider the interim contract-renewal stage. If $\mu=0$ so that the employer is convinced that her partner is of type $\theta_{L}$, she will opt for continuation only if the corresponding second-period surplus exceeds her expected utility from switching to another worker given the observed investment levels $y_{W L}$ and $y_{E}$. This can be stated as $\pi \theta_{H}+(1-\pi) \theta_{L}$ $<F\left(y_{W L}, y_{E}\right)+\theta_{L}$, or

${ }^{8}$ In the proof of proposition 1, I show that the degenerate belief system postulated above is consistent with the Intuitive Criterion. Given any nondegenerate belief system where $\mu\left(\theta_{H} \mid P_{1}, y_{W}\right)$ is increasing in $P_{1}$ and $y_{W}$ (i.e., according to which a better performance and a higher investment level does not decrease the probability that the employer faces a $\theta_{H}$-worker) and given a strategy profile that is consistent with these beliefs, the $\theta_{H}$-worker can credibly and beneficially signal his type by deviating to a strategy $\left(e, y_{W}\right)$ due to the performance gap $\theta_{H}-\theta_{L}$ between the two worker types. 


$$
\theta_{H}-\theta_{L}<\frac{F\left(y_{W L}, y_{E}\right)}{\pi} .
$$

The expected continuation surplus is $F\left(y_{W L}, y_{E}\right)+(1-\pi)\left(\theta_{H}-\theta_{L}\right)$ if $\mu=1$ and $F\left(y_{W L}, y_{E}\right)-\pi\left(\theta_{H}-\theta_{L}\right)$ if $\mu=0$. Then according to the proportional solution, the negotiated wages are

$$
w_{2}\left(1, y_{W H}, y_{E}\right)=\beta\left[F\left(y_{W H}, y_{E}\right)+(1-\pi)\left(\theta_{H}-\theta_{L}\right)\right]+w_{R}
$$

and

$$
w_{2}\left(1, y_{W L}, y_{E}\right)=\beta\left[F\left(y_{W L}, y_{E}\right)-\pi\left(\theta_{H}-\theta_{L}\right)\right]+w_{R}
$$

for $\mu=1$ and $\mu=0$, respectively. Recall that investment decisions are made simultaneously, before the employer observes performance during the first contract. Thus, given a pair of investment levels and the employer's beliefs $\mu$, at the stage where investment decisions are made, the expressions of the worker's and the employer's expected utilities are, respectively,

$$
\begin{aligned}
U_{W i}^{I} & =-y_{W i}+b w_{2}\left(\mu, y_{W i}, y_{E}\right)+(1-b) w_{R}, \\
U_{E}^{I} & =-y_{E}+b V+(1-b)\left[\pi \theta_{H}+(1-\pi) \theta_{L}-w_{R}\right] .
\end{aligned}
$$

First, I construct below a nonscreening PBE with continuation to period two and show that any such PBE must be of the separating type. That is, the employer learns the incumbent worker's type at the end of period one (though she is incompletely informed at the investment stage) and opts for continuation no matter the realized type of the incumbent worker. The following optimality conditions must hold. The $\theta_{H^{-}}$ worker's equilibrium investment strategy satisfies

$$
y_{W H}^{*}>0 \quad \text { if } \beta \frac{\partial F\left(y_{W H}^{*}, y_{E}^{*}\right)}{\partial y_{W}}=1
$$

I confine the analysis to the case $w_{2}\left(1, y_{W H}^{*}, y_{E}^{*}\right)-w_{R} \geq y_{W H}^{*}$ so that $U_{W H}^{I} \geq w_{R}$ for $b=1$. Otherwise, if $U_{W H}^{I}<w_{R}$ the $\theta_{H}$-worker would optimally set $y_{W H}=0$ and guarantee himself the reservation wage $w_{R}$. In equilibrium, the $\theta_{L}$-worker determines $y_{W L}^{*}$ according to

$$
y_{W L}^{*}>0 \quad \text { if } \beta \frac{\partial F\left(y_{W L}^{*}, y_{E}^{*}\right)}{\partial y_{W}}=1
$$


and

$$
\beta\left[F\left(y_{W L}^{*}, y_{E}^{*}\right)-\pi\left(\theta_{H}-\theta_{L}\right)\right]-w_{R} \geq y_{W L}^{*},
$$

and $y_{W L}^{*}=0$ otherwise. Note that the $\theta_{L}$-worker's optimal investment strategy is contingent on the employer's continuation strategy. He will choose a positive investment $y_{W L}^{*}>0$ to negotiate the wage $w_{2}\left(0, y_{W L}^{*}\right.$, $\left.y_{E}^{*}\right)$ and stay for the second period only if this option promises a positive return, as stated in (5). Comparing (5) and (4) reveals that $y_{W H}^{*}=y_{W L}^{*}$ if $y_{W L}^{*}>0$. Note also that $w_{2}\left(0, y_{W L}^{*}, y_{E}^{*}\right)>w_{R}$ if and only if $F\left(y_{W L}^{*}, y_{E}^{*}\right)$ $>\pi\left(\theta_{H}-\theta_{L}\right)$, that is, if and only if the continuation surplus with a $\theta_{H}$-worker is positive, hence (3) is implied if (5) holds. As for the employer's optimal investment $y_{E}^{*}$, it satisfies the first-order condition

$$
1=(1-\beta) \frac{\partial F\left(y_{W i}^{*}, y_{E}^{*}\right)}{\partial y_{E}} .
$$

Let $\phi(\cdot)$ denote the inverse of $d(\cdot)$, the strictly concave effort disutility function. Any nonscreening equilibrium has the properties listed below. PROPOSITION 1.

i) A nonscreening $\mathrm{PBE}$ induces continuation of the relationship through the second period with both worker types. The $\theta_{L}$-worker exerts zero effort while the $\theta_{H}$-worker exerts the effort $e_{H}^{*}=\max \left\{0, \bar{e}_{L}-\left(\theta_{H}\right.\right.$ $\left.\left.-\theta_{L}\right)\right\}$ where

$$
\bar{e}_{L}=\phi\left(w_{2}\left(1, y_{W i}^{*}, y_{E}^{*}\right)-w_{2}\left(0, y_{W i}^{*}, y_{E}^{*}\right)\right),
$$

which signals his type. The employer's first-period strategy is to offer the wage

$$
w_{1}^{*}=2 w_{R}+y_{W i}^{*}-w_{2}\left(0, y_{W i}^{*}, y_{E}^{*}\right)
$$

ii) Any nonscreening contract that induces continuation with only the $\theta_{H}$-worker is dominated by contracts that perform screening.

iii) Application of the Intuitive Criterion implies that the worker types always separate as the first contract expires. That is, all PBE are of the separating type, and $w_{1}^{*}<w_{R}$.

A contract $\left\{w_{1}^{*}\right\}$ that is accepted by both worker types induces continuation to the second period with probability one, for no worker would accept the initial offer below his reservation wage if the employer had an incentive to terminate the relationship. The equilibrium offer wage in (8) is derived from $\theta_{L}$-workers' indifference condition, as the employer can always modify the offer wage to bind the participation constraint of 
$\theta_{L}$-workers. The incumbent $\theta_{H^{-}}$-worker obtains a positive surplus. Using (8) and the definition of $w_{2}\left(\mu, y_{W}, y_{E}\right)$, the employer's expected utility in a nonscreening $\mathrm{PBE}$ can be written as

$$
\begin{aligned}
U_{E}= & \pi\left[2 \theta_{H}+e_{H}^{*}+F\left(y_{W i}^{*} y_{E}^{*}\right)\right]+(1-\pi)\left[2 \theta_{L}+F\left(y_{W i s}^{*} y_{E}^{*}\right)\right] \\
& -\pi\left[w_{2}\left(1, y_{W i s}^{*} y_{E}^{*}\right)-w_{2}\left(0, y_{W i s}^{*} y_{E}^{*}\right)\right]-w_{R}-y_{E}^{*}-y_{W i}^{*} \\
= & 2\left[\pi \theta_{H}+(1-\pi) \theta_{L}-w_{R}\right]+F\left(y_{W i}^{*} y_{E}^{*}\right) \\
& -\pi \beta\left(\theta_{H}-\theta_{L}\right)+\pi e_{H}^{*}-y_{E}^{*}-y_{W i}^{*}
\end{aligned}
$$

where $e_{H}^{*}=\max \left\{0, \bar{e}_{L}-\left(\theta_{H}-\theta_{L}\right)\right\}$. The employer invests $y_{E}^{*}$ on the incumbent worker's specific human capital under the risk that the investment may lock her in with a (potentially improved) $\theta_{L}$-worker. A byproduct of the process is a positive effort $e_{H}^{*}$ by the $\theta_{H}$-worker who signals his type during the first period. Combining the result of parts $i$ and ii of proposition 1 yields the dynamics of wages: $w_{1}<w_{R}<w_{2}$.

The critical condition for the existence of a nonscreening PBE with unconditional continuation is (5). The $\theta_{L}$-worker's optimal investment on specific human capital must be sufficiently productive to cover at least his investment cost, by improving his bargaining power and generating a higher second-period wage. Otherwise, the $\theta_{L}$-worker will choose $y_{W L}^{*}$ $=0$, and the employer will opt for switching at the end of period one. But then inducing a nonscreening PBE cannot be optimal, as stated in part iii of proposition 1.

Consider now screening PBE where the corresponding strategies are denoted through "hats." As mentioned, the employer cannot screen out $\theta_{L}$-workers through a first-period wage above $w_{R}$. She thus has to choose an appropriate wage $w_{1}<w_{R}$ that attracts only $\theta_{H}$-workers. The employer's optimal investment $\hat{y}_{E}$ maximizes (2) given $\hat{y}_{W H}$, where $\pi \theta_{H}$ $+(1-\pi) \theta_{L}$ should now be replaced by $\theta_{H}$, and $V=\theta_{H}+F\left(\hat{y}_{W H}, \hat{y}_{E}\right)$ - $w_{2}\left(1, \hat{y}_{W H}, \hat{y}_{E}\right)$. Hence, $\hat{y}_{E}$ satisfies the equilibrium condition

$$
1=\frac{\partial F\left(\hat{y}_{W H}, \hat{y}_{E}\right)}{\partial y_{E}}-\frac{\partial w_{2}\left(1, \hat{y}_{W H}, \hat{y}_{E}\right)}{\partial y_{E}},
$$

while $\hat{y}_{W H}$ satisfies (4) as in the nonscreening PBE. Obviously, a screening $\mathrm{PBE}$ must involve continuation (with the $\theta_{H}$-worker). Otherwise, since $w_{1}<w_{R}$, no $\theta_{H}$-worker would accept the initial contract. A $\theta_{H}$-worker accepts the wage below his reservation wage because he expects (as fulfilled in equilibrium) that he will be able to capture an offsetting surplus $w_{2}\left(1, \hat{y}_{W H}, \hat{y}_{E}\right)-w_{R}$ from continuation through the second period.

Proposition 2. In a screening PBE, the initial contract $\hat{w}_{1}<w_{R}$ is 
accepted by only $\theta_{H^{-}}$workers. In the first period, the incumbent $\theta_{H^{-}}$ worker's strategy is $\hat{e}_{H}=\max \left\{0, \bar{e}_{L}-\left(\theta_{H}-\theta_{L}\right)\right\}$ where

$$
\bar{e}_{L}=\phi\left(\hat{w}_{1}-2 w_{R}-\hat{y}_{W H}+w_{2}\left(1, \hat{y}_{W H}, \hat{y}_{E}\right)\right),
$$

while $\theta_{L}$-workers are indifferent between rejecting and accepting the contract, then exerting the effort $\bar{e}_{L}$ and investing $\hat{y}_{W H}$. The employer can always guarantee herself the expected utility level

$$
\underline{U}_{E}=2\left[\theta_{H}-w_{R}\right]+F\left(\hat{y}_{W H}, \hat{y}_{E}\right)-\hat{y}_{W H}-\hat{y}_{E} .
$$

The lower bound to the employer's screening PBE utility obtains when the $\theta_{H^{-}}$worker credibly signals his type through zero effort. This is not necessarily the maximum expected utility of the employer. As I show below, the alternative option of inducing $\hat{e}_{H}>0$ has a cost in the form of a higher first-period wage but a benefit in the form of improved first-period performance. The corresponding equilibrium conditions are as follows: $\hat{e}_{H}=\bar{e}_{L}-\left(\theta_{H}-\theta_{L}\right)>0, \hat{y}_{E}$ must satisfy (10), and $\hat{w}_{1}$ must satisfy

$$
1=\frac{\partial \phi\left(\hat{w}_{1}-2 w_{R}-\hat{y}_{W H}+w_{2}\left(1, \hat{y}_{W H}, \hat{y}_{E}\right)\right)}{\partial d} .
$$

Now an upper bound $\bar{w}_{1}<w_{R}$ on first-period wages $\hat{w}_{1}$ that perform screening and induce a positive effort is implied by the possibility that a $\theta_{L}$-worker accepts the contract and locks the employer in for the second period by investing his best reply to $\hat{y}_{E}$, denoted $y_{W L}\left(\hat{y}_{E}\right)$. Note that $y_{W L}\left(\hat{y}_{E}\right)=\hat{y}_{W H}$, that is, the two worker types' investments are the same, because the pair $\left(\hat{y}_{W L}, \hat{y}_{E}\right)$ constitutes mutual best replies. Acceptance of the initial contract by $\theta_{L}$-workers would upset the screening PBE, however. There is a maximal wage $\bar{w}_{1}$ that performs screening and induces the effort $\hat{e}_{H}$ by the $\theta_{H}$-worker, while making $\theta_{L}$-workers indifferent between rejecting and accepting $\left\{\bar{w}_{1}\right\}$ to invest $y_{W L}\left(\hat{y}_{E}\right)=\hat{y}_{W H}$. Thus the latter strategy must yield $\theta_{L}$-workers zero expected surplus at the wage $\bar{w}_{1}=2 w_{R}+\hat{y}_{W H}-w_{2}\left(0, \hat{y}_{W H}, \hat{y}_{E}\right)$. Using this wage expression and strict concavity of $\phi(\cdot)$, a necessary condition for an interior solution satisfying (13) and $\hat{w}_{1} \leq \bar{w}_{1}<w_{R}$ can be derived by letting $\hat{w}_{1} \rightarrow \bar{w}_{1}$ in (13):

$$
\frac{\partial \phi\left(w_{2}\left(1, \hat{y}_{W H}, \hat{y}_{E}\right)-w_{2}\left(0, \hat{y}_{W H}, \hat{y}_{E}\right)\right)}{\partial d}<1 .
$$


There exists a wage $\hat{w}_{1} \leq \bar{w}_{1}$ satisfying (13) if (14) holds. ${ }^{9}$ Then, condition (10), which determines the employer's equilibrium investment, simplifies to $1=\partial F\left(\hat{y}_{W H}, \hat{y}_{E}\right) / \partial y_{E}$, and the employer's equilibrium expected utility is

$$
U_{E}=2 \theta_{H}-\hat{w}_{1}-w_{R}+\hat{e}_{H}+F\left(\hat{y}_{W H}, \hat{y}_{E}\right)-w_{2}\left(1, \hat{y}_{W H}, \hat{y}_{E}\right)-\hat{y}_{E} .
$$

To induce effort during the screening process, the employer must offer a wage significantly higher than $\hat{w}_{1}$ (the wage that induces the zero-effort screening PBE). This is beneficial for the employer if $\hat{e}_{H}-\hat{w}_{1}>w_{2}(1$, $\left.\hat{y}_{W H}, \hat{y}_{E}\right)-w_{R}-\hat{y}_{W H}>0$, that is, if the equilibrium effort $\hat{e}_{H}$ and the performance so induced are sufficiently high to offset the wage differential $\hat{w}_{1}-\hat{\underline{w}}_{1}$. I stress the following point: even though $U_{E}>\underline{U} E$, so that efficient screening stipulates inducing a screening equilibrium with positive effort, this may be impossible because $\hat{w}_{1}$ as defined through (13) may well exceed $\bar{w}_{1}$. The following result obtains.

Proposition 3. It may be impossible to induce the efficient screening equilibrium given the employer's postcontract investment incentives and anticipated continuation decision. In this case, the employer offers a contract $\left\{\hat{w}_{1}\right\}$ that distorts the $\theta_{H}$-worker's effort $\hat{e}_{H}$. As a result, her expected utility from the screening PBE falls, and she may choose to induce either a zero-effort equilibrium or a nonscreening equilibrium.

The employer's most preferred outcome is certainly to build a relationship with a $\theta_{H}$-worker from the outset and invest jointly on her partner's specific human capital for continuation. The most efficient way of screening may involve getting some improved performance in the first period from the $\theta_{H}$-worker by offering a relatively high first-period wage $\hat{w}_{1}$. However, proposition 3 states that the employer's investment incentives may well upset this objective by attracting $\theta_{L}$-workers. In other words, $\hat{w}_{1}$ may exceed the minimal screening wage $\bar{w}_{1}$. A $\theta_{L}$-worker may accept the wage $\hat{w}_{1}$ and lock the employer in for the second period. The employer's investment $\hat{y}_{E}$ and the $\theta_{L}$-worker's investment $y_{W L}\left(\hat{y}_{E}\right)$ $=\hat{y}_{W H}$ would generate a sufficient improvement in his specific human capital so that ex post the employer has no choice but to continue with the $\theta_{L}$-worker. The employer, then, cannot induce a screening PBE with efficient effort. She has to distort $\hat{w}_{1}$, hence the effort $\hat{e}_{H}$, downward, which decreases her expected utility.

The problem identified above may lead the employer to commit her-

${ }^{9}$ Condition (14) is likely to hold if the differential utility $U_{W H}^{L}-U_{W L}^{I}$, as viewed from the investment stage, is large enough. One of the factors affecting the utility differential $U_{W H}^{I}-U_{W L}^{I}$ is the "innate" performance gap, $\theta_{H}-\theta_{L}$, through the support of the set of mutually beneficial second-period wages containing $w_{2}$. 
self, if possible, to an investment strategy sufficiently below $\hat{y}_{E}$ and make that commitment public at the outset. Modifying the investment technology to decrease its productivity is another possibility. This will relax the screening constraint and allow for a higher maximal screening wage $\bar{w}_{1}$, thus potentially reducing the effectiveness of the conflict between investment and efficient screening. Proposition 4 below considers the rather extreme case of zero productivity to show that the screening constraint can be relaxed this way. Since all PBE are of the separating type by proposition 1 , the employer will never choose continuation with a $\theta_{L^{-}}$ worker because the expected matching value of an outsider, $\pi \theta_{H}+(1$ $-\pi) \theta_{L}$, exceeds $\theta_{L}$. Then a nonscreening contract must induce continuation with only the $\theta_{H^{-}}$-worker, and the corresponding first-period wage is $w_{1}=w_{R}$.

Proposition 4. In the absence of investments on specific human capital, (i) any increasing wage profile with $w_{1}<w_{R}$ induces a screening PBE (now the maximal screening wage is $\bar{w}_{1}=w_{R}$ ); and (ii) in a screening PBE, the $\theta_{H}$-worker exerts the effort $e_{H}^{S}=\bar{e}_{L}-\left(\theta_{H}-\theta_{L}\right)$, where $\bar{e}_{L}=\phi\left(w_{1}^{S}-w_{R}+\beta\left(\theta_{H}-\theta_{L}\right)\right)$, and the optimal screening wage $w_{1}^{S}$ satisfies $1=\partial \phi\left(w_{1}^{S}-w_{R}+\beta \pi\left(\theta_{H}-\theta_{L}\right)\right) / \partial d$. Such an equilibrium exists if

$$
1>\frac{\partial \phi\left(\beta \pi\left(\theta_{H}-\theta_{L}\right)\right)}{\partial d},
$$

which is weaker than the corresponding condition in the presence of an investment technology.

\section{Conclusion}

This article shows that employers' incentives to invest on specific human capital jointly with incumbent workers may conflict with their objective to induce an efficient screening process. A higher initial wage must be offered when efficient screening stipulates that workers on short-term contracts exert effort in signaling a good match parameter, yielding temporarily improved worker performance as a by-product. This high wage may upset the employer's screening objective, however. Workers with a bad match parameter may find it worthwhile to penetrate into the relationship and invest and generate sufficient improvement in their specific human capital to lock the employer in for the future. Then, since she cannot induce the efficient screening equilibrium, the employer would have two options left. Either she induces an inefficient screening equilibrium or she credibly decreases the productivity of the technology generating specific human capital. This potential explanation for subop- 
timal expenditures on on-the-job training is entirely different from those based on "inappropriable rents" in firms' investments on young employees.

All equilibria of this model display an increasing pattern of wages. ${ }^{10}$ Many other features of the equilibria of this model accord well with the empirical studies that suggest a significant combined effect of matching, screening, and human capital investments on wage profiles (e.g., Brown 1989; Topel 1991; and Topel and Ward 1992). Sicherman and Galor (1990) present evidence that worker-firm matching is resolved and specific capital is accumulated early in a worker's career. The personnel data analyzed by Baker et al. (1994) reveal that learning and human capital accumulation affect wage profiles along careers within firms. A message of the present analysis is that empirical studies aiming at explaining wage profiles should take into account the potential distortion introduced by the conflict between employers' objectives to screen efficiently while investing on specific human capital. I have shown that this distortion can contribute to the steepness of the wage profile, and thus that the simultaneous presence of these two objectives (screening and investing) should be consistent with a wide range of wage profiles with different slopes.

One implication of this model is that a more productive investment technology is likely to generate a steeper wage profile when matching and screening have important efficiency consequences. Another implication is that the larger the "innate performance gap" between potential worker types - thus the more significant the adverse selection problem-the steeper is the wage profile, keeping other factors constant. The second prediction is also derived in on-the-job training models with turnover costs (see Waldman 1984; Greenwald 1986; and Demougin and Siow 1996). It finds empirical support in Loh's (1994) findings that workers have significantly steeper wage profiles in jobs with probationary contracts and that a steep wage profile is a good indicator of whether the job has a probationary contract. The first prediction awaits a rigorous empirical test, ideally using personnel data from firms in order to generate reliable estimates for the productivity of both the worker's and the employer's investments on specific human capital. The most important practical problem lies in assessing the joint and isolated effects of matching concerns and bilateral human capital investments on the wage profile. This model implies that the joint effect can be substantially larger than the isolated effects.

The model can be modified or extended in several directions. An important modification is to replace specific with general human capital and introduce labor market imperfections (which, as Acemoglu and

${ }^{10}$ Prendergast (1999) surveys the literature explaining and empirically verifying the rising pattern of wages throughout careers. 
Pischke $[1998 a, 1998 b]$ have shown, are necessary to generate positive general investments by the employer). The reservation wage of the worker would then be increasing in his stock of general human capital, but continuation would be mutually beneficial and the employer would capture a return on her investment. Labor market imperfections drive a wedge between the minimum wage for which the employee will work and the maximum wage the employer will pay. Negotiations, as in the present model, determine where within the wedge the wage will lie. Though these features are similar, the analysis in the case of general human capital differs in two important respects. First, screening becomes more problematic because improved general human capital increases the worker's reservation wage: workers with poor matching parameters may penetrate into the relationship, get some investment on their general human capital, and later switch away if switching costs are not too high. Second, given a matching outcome, the continuation surplus and, therefore, the employer's incentives to invest on general human capital are determined by the significance of labor market imperfections. (In the case of specific human capital, these are determined by the productivity of the investment technology.) Though the distinction between specific and general human capital vanishes in the limit where the two contracting parties are completely locked in and isolated from market forces, for intermediate degrees of labor market imperfections (with nonprohibitive switching costs), the incumbent worker's improved outside option limits the continuation surplus and erodes the employer's incentives to invest on general human capital. Thus the shape of the wage profile and the effectiveness of the potential conflict between the employer's matching motive and investment incentives would depend on an additional variable: the degree of labor market imperfections. An extension of the present model in this direction may identify new factors shaping wage profiles in firms.

\section{Appendix}

\section{Proofs}

Proof of proposition 1.

i) Fixing other players' equilibrium strategies as described in the proposition statement, a $\theta_{L}$-worker who puts in zero effort expects the utility

$$
U_{W L}=w_{1}^{*}-y_{W i}^{*}+w_{2}\left(0, y_{W i}^{*} y_{E}^{*}\right) \geq 2 w_{R} .
$$

It is possible to define an effort level $\bar{e}_{L}$ for the $\theta_{L}$-worker, such that $\bar{e}_{L}$ is just enough to close the innate performance gap $\theta_{H}-\theta_{L}$ and imitate the $\theta_{H}$-worker's performance, provided that the employer interprets the resulting performance $\bar{e}_{L}+\theta_{L} \geq \bar{P}$ as coming from a $\theta_{H}$-worker. If this imitation strategy of the $\theta_{L}$-worker is not beneficial, then the two worker types must separate in equilibrium. The $\theta_{L}$-worker will be indifferent 
between exerting $\bar{e}_{L}$ to imitate the performance level $P_{H}^{*}=\bar{P}$ and playing his zero-effort equilibrium strategy if

$$
w_{1}^{*}-y_{W i}^{*}+w_{2}\left(0, y_{W i}^{*}, y_{E}^{*}\right)=w_{1}^{*}-y_{W i}^{*}-d\left(\bar{e}_{L}\right)+w_{2}\left(1, y_{W i}^{*} y_{E}^{*}\right) .
$$

Inverting $d\left(\bar{e}_{L}\right)$ and solving yields the expression for $\bar{e}_{L}$ given in (7). This effort level, as I show below, will be used in determining the threshold performance level $\bar{P}$. On the other hand, given $\bar{P}$, the $\theta_{H^{-}}$worker's optimal effort strategy is $e_{H}^{*}=\max \left\{0, \bar{P}-\theta_{H}\right\}$. I can now define the threshold performance level in the employer's belief system as $\bar{P}=\bar{e}_{L}$ $+\theta_{L}$, which, if $e_{H}^{*}>0$, is also equal to $e_{H}^{*}+\theta_{H}$. Therefore, in any separating PBE with positive effort, $\bar{e}_{L}+\theta_{L}=e_{H}^{*}+\theta_{H}$. As for the $\theta_{L}$-worker's equilibrium strategy, $e_{L}^{*}=0$ is an optimal effort strategy by the tie-breaking assumption. Exerting the maximal effort $\bar{e}_{L}$ to imitate the $\theta_{H}$-worker yields the same reservation utility $w_{R}$, whereas all other effort strategies generate a lower expected utility.

Optimality of the investment strategies given the belief system of the employer is discussed in the text. I show below that the postulated belief system is consistent with the Intuitive Criterion. Note that $P_{H}^{*}$ is a convincing signal that $\theta=\theta_{H}$. If the threshold performance level $P$ were above $P_{H}^{*}$, then the $\theta_{H}$-worker could still send the performance signal $P_{H}^{*}$ that the $\theta_{L}$-worker could not and which, by the Intuitive Criterion, should lead to $\mu=1$. As for the threshold investment level $\bar{y}$ in the employer's beliefs, given $\bar{P}=P_{H}^{*}$, suppose by way of contradiction that $\bar{y}>y_{W i}^{*}$ and $\mu=1$ only for $y_{W i} \geq \bar{y}$ is part of a belief system satisfying the Intuitive Criterion. Let the employer's best reply to $\bar{y}$ be $y_{E}^{*}(\bar{y})$. Note, however, that $\bar{y}>y_{W i}^{*}$ is not a best reply to $y_{E}^{*}(\bar{y})$. These beliefs are forcing the $\theta_{H}$-worker to invest $\bar{y}$, even more than $y_{W i}^{*}$, in order to signal his type. If the $\theta_{H}$-worker deviates to his best reply $y_{W H}^{*}\left(y_{E}^{*}(\bar{y})\right)$ and keeps providing the performance $P_{H}^{*} \geq \bar{P}$, this deviation is bad only for the $\theta_{L}$-worker, and according to the Intuitive Criterion, $\mu=1$. It follows that the threshold investment level $\bar{y}$ in the employer's beliefs should not exceed $y_{W i}^{*}$, which is a best reply to $y_{E}^{*}$ for both worker types, as stipulated by conditions (4), (5), and (6).

The optimal contract $\left\{w_{1}^{*}\right\}$ in a nonscreening PBE satisfies (8). To see this, note that the $\theta_{H^{-}}$-worker's equilibrium expected utility and participation constraint are

$$
U_{W H}=w_{1}-d\left(e_{H}^{*}\right)-y_{W i}^{*}+w_{2}\left(1, y_{W i}^{*} y_{E}^{*}\right) \geq w_{R} \text {. }
$$

Since $\bar{e}_{L}$ is not affected by $w_{1}$ (see [7]), $w_{1}$ should be chosen as low as possible. The lower bound for $w_{1}$ in a nonscreening contract binds the participation constraint (A1) of the $\theta_{L}$-worker, which yields the result stated in (8), and (5) implies $w_{1}^{*}<w_{R}$. Note that $U_{W L} \geq w_{R}$ because $e_{H}^{*}$ $\leq \bar{e}_{L}$.

ii) Suppose that (3) does not hold, so that the employer terminates the relationship if $\mu=0$. The $\theta_{L}$-worker's corresponding strategies are $y_{W L}^{*}$ 
$=0$ and $e_{L}^{*}=0$, which yields the utility $U_{W L}=w_{1}+w_{R}$. The $\theta_{H}$-worker determines his equilibrium effort according to $e_{H}^{*}=\max \{0$, $\left.\bar{e}_{L}-\left(\theta_{H}-\theta_{L}\right)\right\}$, where

$$
\bar{e}_{L}=\phi\left(w_{2}\left(1, y_{W i}^{*}, y_{E}^{*}\right)-w_{R}-y_{W i}^{*}\right) .
$$

As in case (i), exerting the effort $\bar{e}_{L}$ to imitate the $\theta_{H}$-worker's performance yields the $\theta_{L}$-worker the expected utility he would obtain by setting effort equal to zero. Since $\bar{e}_{L}$ is independent of $w_{1}$, the employer should again set $w_{1}$ as low as possible, which in this case is $w_{1}^{*}=w_{R}$. Decreasing $w_{1}$ by arbitrarily small $\varepsilon$ would then screen out the $\theta_{L}$-worker without significantly affecting equilibrium effort and generate an improvement of $(1-\pi)\left(\theta_{H}-\theta_{L}\right)$ in expected first-period performance. Nonscreening contracts are therefore dominated.

iii) Given the $\theta_{H}$-worker's advantage in providing performance, the Intuitive Criterion eliminates all potential pooling equilibria (where performance and investment strategies are not informative). To satisfy the Intuitive Criterion, the employer's belief system must put zero probability on $\theta=\theta_{L}$ when a sufficiently high performance is observed. It is impossible to construct a pooling equilibrium belief system that satisfies this requirement.

Since any nonscreening PBE must be of the type presented in part (i), I conclude that $w_{1}<w_{R}$. On the other hand, it is impossible to induce a screening equilibrium through $w_{1}>w_{R}$, for a $\theta_{L}$-worker would accept the offer, set effort and investment equal to zero, and return to his outside option as the contract expires. Therefore, $w_{1}^{*}<w_{R}$ in any PBE. Q.E.D.

Proof of proposition 2. The employer's decision to extend the relationship to period two is clearly optimal whenever $\mu=1$. Determining the threshold performance and investment levels as $\bar{P}=\hat{P}_{H}$ and $\bar{y} \leq \hat{y}_{W H}$ for beliefs off the equilibrium path satisfies the Intuitive Criterion and is consistent with the equilibrium strategies presented below. The details are omitted, for they follow from arguments similar to those presented in case $\mathrm{i}$ of proposition 1 . The investment level $\hat{y}_{W H}$ satisfies (4), and $\hat{P}_{H}$ $=\theta_{H}+\hat{e}_{H}$ where $\hat{e}_{H}=\max \left\{0, \bar{e}_{L}-\left(\theta_{H}-\theta_{L}\right)\right\}$, and $\bar{e}_{L}$ is defined by (11). Since $w_{2}\left(1, \hat{y}_{W H}, \hat{y}_{E}\right)$ and $\hat{y}_{W H}$ are unique, $\bar{e}_{L}$ is unique and so is $\hat{e}_{H}$. The employer can always induce a zero-effort equilibrium through the wage

$$
\underline{\hat{w}}_{1}=2 w_{R}+\hat{y}_{W H}-w_{2}\left(1, \hat{y}_{W H}, \hat{y}_{E}\right)
$$

binding the $\theta_{H^{-}}$-worker's participation constraint, which yields her the expected utility level given in (12). Q.E.D.

Proof of proposition 3. The $\theta_{H}$-worker's effort strategy in a screening $\mathrm{PBE}$ is $\hat{e}_{H}=\bar{e}_{L}-\left(\theta_{H}-\theta_{L}\right)$, where $\bar{e}_{L}=\phi\left(\hat{w}_{1}-w_{R}-\hat{y}_{W H}\right.$ $\left.+\beta F\left(\hat{y}_{W H}, \hat{y}_{E}\right)+\beta \pi\left(\theta_{H}-\theta_{L}\right)\right)$. The optimal first-period wage $\hat{w}_{1}$ balances the costs and benefits, maximizing the employer's expected continuation utility: 


$$
1=\frac{\partial \phi\left(\hat{w}_{1}-w_{R}-\hat{y}_{W H}+\beta F\left(\hat{y}_{W H}, \hat{y}_{E}\right)+\beta \pi\left(\theta_{H}-\theta_{L}\right)\right)}{\partial d} .
$$

However, $\hat{w}_{1}$ must satisfy an additional condition to screen out $\theta_{L^{-}}$ workers. Let $y_{W L}\left(\hat{y}_{E}\right)$ maximize $\beta F\left(y_{W L}, \hat{y}_{E}\right)-y_{W L}$ given $\hat{y}_{E}$. Note that $y_{W L}\left(\hat{y}_{E}\right)=\hat{y}_{W H}$ because $\hat{y}_{W H}$ satisfies the same equilibrium condition. Then the screening constraint becomes $\hat{w}_{1} \leq \bar{w}_{1}$, where

$$
\bar{w}_{1}=w_{R}+\hat{y}_{W H}-\beta\left[F\left(\hat{y}_{W H}, \hat{y}_{E}\right)-(1-\pi)\left(\theta_{H}-\theta_{L}\right)\right] .
$$

A first-period wage that satisfies both (A3) and $\hat{w}_{1} \leq \bar{w}_{1}$ may not exist. In that case, the employer has to distort $w_{1}$ downward to satisfy this condition and induce a lower equilibrium effort, which reduces her expected utility. The resulting expected utility may be less than what she obtains in a screening PBE without effort, or the utility in (9) corresponding to a nonscreening PBE. Q.E.D.

Proof of proposition 4.

i) Since all PBE are of the separating type and the employer sets $b=0$ if $\mu=0$, the $\theta_{L}$-worker's expected utility from accepting the contract is simply $w_{1}$. Therefore, $\bar{w}_{1}=w_{R}$, and any wage $w_{1}<w_{R}$ induces a screening PBE.

ii) Derivation of strategies and beliefs in a screening PBE follow the arguments given in the proof of proposition 2 . The $\theta_{H}$-worker exerts the minimal signaling effort $e_{H}^{S}$. I show below that in the absence of investments, the condition $\hat{w}_{1} \leq \bar{w}_{1}$ is more likely to hold. With the investment technology, using (A4) in (A3) as $\hat{w}_{1} \rightarrow \bar{w}_{1}$, the condition $\hat{w}_{1} \leq \bar{w}_{1}$ requires that the right-hand side of (A3) not exceed one, by strict concavity of $\phi(\cdot)$. That is, ${ }^{11}$

$$
1 \geq \frac{\partial \phi\left(\beta(2 \pi-1)\left(\theta_{H}-\theta_{L}\right)\right)}{\partial d} .
$$

Without the investment technology, the corresponding condition, as $w_{1}^{S}$ $\rightarrow \bar{w}_{1}=w_{R}$, is $1 \geq \partial \phi\left(\beta \pi\left(\theta_{H}-\theta_{L}\right)\right) / \partial d$ as stated in (16). Note that $\phi\left(\beta \pi\left(\theta_{H}-\theta_{L}\right)\right)>\phi\left(\beta(2 \pi-1)\left(\theta_{H}-\theta_{L}\right)\right)$ for all $\pi<1$ because $\phi(\cdot)$ is increasing, which implies

$$
\frac{\partial \phi\left(\beta \pi\left(\theta_{H}-\theta_{L}\right)\right)}{\partial d}<\frac{\partial \phi\left(\beta(2 \pi-1)\left(\theta_{H}-\theta_{L}\right)\right)}{\partial d} \geq 1
$$

${ }^{11}$ The investment strategy does not appear in (A5). This is a pure consequence of the fact that under proportional solutions to the bargaining problem, the incumbent $\theta_{H}$-worker and a $\theta_{L}$-worker who may penetrate into the relationship are investing the same $\hat{y}_{W i}$. As $\hat{w}_{1} \rightarrow \bar{w}_{1}$, the expression of the efficient screening constraint in (A5) simplifies considerably. 
by strict concavity of $\phi(\cdot)$. It follows that (A5) implies (16). Q.E.D.

\section{References}

Abe, Yukiko. "Specific Capital, Adverse Selection and Turnover: A Comparison of the United States and Japan." Journal of the Japanese and International Economies 8 (April 1994): 272-94.

Acemoglu, Daron, and Pischke, Jörn-Steffen. "The Structure of Wages and Investment in General Training." Working Paper no. 1833. London: Center for Economic Policy Research, 1998. (a)

"Why Do Firms Train? Theory and Evidence." Quarterly Journal of Economics 113 (May 1998): 225-48. (b)

Bac, Mehmet. "Opportunism and the Dynamics of Incomplete Contracts." International Economic Review 33 (August 1993): 663-83.

- "Bilateral Relationships Governed by Incomplete Contracts." Journal of Institutional and Theoretical Economics 153 (June 1997): 319-33.

- "To Invest or Screen Efficiently: A Potential Conflict in Relationships Governed by Incomplete Contracts.” Photocopied. Bilkent University, Ankara, Turkey, 1998.

Bac, Mehmet, and Saglam, Ismail. "Managerial Defections, Promotion Criteria and Firm Growth." International Journal of Industrial Organization 17 (October 1999): 917-40.

Baker, George; Gibbs, Michael; and Holmstrom, Bengt. "The Internal Economics of the Firm: Evidence from Personnel Data.” Quarterly Journal of Economics 109 (November 1994): 881-920.

Brown, James N. "Why Do Wages Increase with Tenure? On-the-Job Training and Life-Cycle Wage Growth Observed within Firms." American Economic Review 79 (December 1989): 971-91.

Demougin, Dominique, and Siow, Aloysius. "Careers in Ongoing Hierarchies.” American Economic Review 84 (December 1994): 1260-77.

_. "Managerial Husbandry and the Dynamics of Ongoing Hierarchies." European Economic Review 40 (August 1996): 1483-99.

Doeringer, Peter, and Piore, Michael. Internal Labor Markets and Manpower Analysis. Lexington, MA: Heath, 1971.

Farrell, Joseph, and Shapiro, Carl. "Optimal Contracts with Lock-In." American Economic Review 79 (March 1989): 51-68.

Greenwald, Bruce C. "Adverse Selection in the Labor Market." Review of Economic Studies 53 (April 1986): 325-47.

Holmstrom, Bengt. "Managerial Incentive Problems-A Dynamic Perspective." In Essays in Economics and Management in Honor of Lars Wablbeck, edited by Bjorn Walross. Helsinki: Swedish School of Economics, 1982.

Laffont, Jean Jacques, and Tirole, Jean. "The Dynamics of Incentive Contracts.” Econometrica 56 (May 1988): 457-78.

Loh, Eng S. "Employment Probation as a Sorting Mechanism." Industrial and Labor Relations Review 47 (April 1994): 471-86. 
Malcomson, James M. “Contracts, Hold-Up, and Labor Markets.” Journal of Economic Literature 35 (December 1997): 1916-57.

Prendergast, Canice. "Career Development and Specific Human Capital Collection." Journal of the Japanese and International Economies 6 (April 1992): 207-27.

- "The Provision of Incentives in Firms." Journal of Economic Literature 37 (March 1999): 7-63.

Sicherman, Nachum, and Galor, Oded. "A Theory of Career Mobility." Journal of Political Economy 98 (February 1990): 169-92.

Topel, Robert. "Specific Capital, Mobility, and Wages: Wages Rise with Job Seniority." Journal of Political Economy 99 (February 1991): 14576.

Topel, Robert, and Ward, Michael. "Job Mobility and the Careers of Young Men." Quarterly Journal of Economics 107 (May 1992): 439-79.

Waldman, Michael. "Job Assignments, Signaling, and Efficiency." RAND Journal of Economics 15 (Summer 1984): 255-67.

Weiss, Andrew. "Human Capital vs. Signaling Explanations of Wages." Journal of Economic Perspectives 9 (Fall 1995): 133-54. 